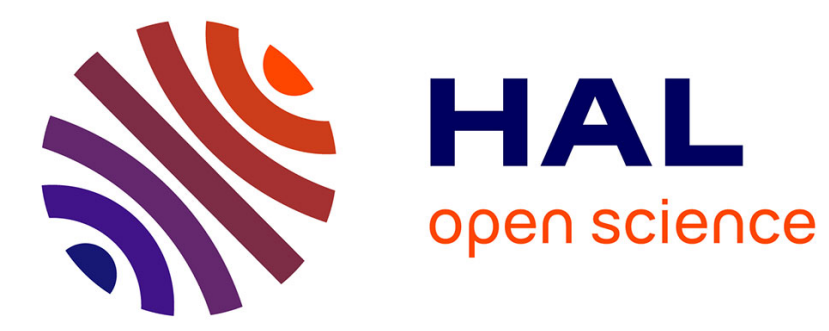

\title{
Sewing Thread Consumption for Different Lockstitches of Class 300 Using Geometrical and Multi-Linear Regression Models
}

\author{
Malek Sarah, Jaouachi Boubaker, Khedher Faouzi, Dominique Adolphe
}

\section{- To cite this version:}

Malek Sarah, Jaouachi Boubaker, Khedher Faouzi, Dominique Adolphe. Sewing Thread Consumption for Different Lockstitches of Class 300 Using Geometrical and Multi-Linear Regression Models. Autex Research Journal, 2020, 20 (4), pp.415-425. 10.2478/aut-2019-0022 hal-03124698

\section{HAL Id: hal-03124698 \\ https://hal.science/hal-03124698}

Submitted on 28 Jan 2021

HAL is a multi-disciplinary open access archive for the deposit and dissemination of scientific research documents, whether they are published or not. The documents may come from teaching and research institutions in France or abroad, or from public or private research centers.
L'archive ouverte pluridisciplinaire HAL, est destinée au dépôt et à la diffusion de documents scientifiques de niveau recherche, publiés ou non, émanant des établissements d'enseignement et de recherche français ou étrangers, des laboratoires publics ou privés. 


\title{
SEWING THREAD CONSUMPTION FOR DIFFERENT LOCKSTITCHES OF CLASS 300 USING GEOMETRICAL AND MULTI-LINEAR REGRESSION MODELS
}

\author{
Malek Sarah $^{1 *}$, Jaouachi Boubaker ${ }^{1}$, Khedher Faouzi $^{1}$, Dominique Adolphe ${ }^{2}$ \\ 1 National School of Engineers of Monastir, University of Monastir, Monastir, Tunisia \\ 2 Ecole Nationale Supérieure d'Ingénieurs Sud Alsace, Université de Haut-Alsace, Mulhouse, France \\ E-mail: maleksarah88@gmail.com
}

\begin{abstract}
:
This paper aims to provide rapid and precise methods to allow industrials to predict the amount of sewing thread needed to sew a garment using different lockstitches of class 300 (301, 301/301, 304, 308, 309, 310, 311, 312, and 315). To avoid unused stocks for each stitch type, a sewing consumption value was determined using a geometrical method of different lockstitch shapes. Furthermore, the relationships between overall geometrical models of the studied lockstitches of class 300 were developed. Indeed, based on the geometrical model of lockstitch type 301, all theoretical models proposed were investigated and proved to be accurate. Moreover, referring to the findings, the prediction of the sewing thread consumption relative to each investigated lockstitch was proposed as a function of the studied input parameters. To improve the established models using geometrical technique, a statistical method was conducted. In addition, based on multi-linear regression, compared geometrical and statistical results were discussed and the coefficient R2 value was determined to evaluate the accuracy of the tested methods. By comparing the estimated thread consumption with the experimental ones, we concluded that the accuracy of the models is significant (R2 ranged from $93.91 \%$ to $99.10 \%$ ), which encourages industrialists to use geometrical models to predict thread consumption. Therefore, the accuracy of prediction using the geometrical method is more accurate than the statistical method regarding the range of $R 2$ (from $92.84 \%$ to $97.87 \%$ ). To classify the significance of all studied parameters, their contributions to the sewing thread consumption behavior were analyzed in the experimental design of interest. It was concluded that the most important parameters affecting thread consumption are stitch width, stitch density, and the gap between two needles. The thickness of fabric has a low contribution to the thread consumption value, whereas the effect of yarn count can be neglected.
\end{abstract}

\section{Keywords:}

Key words: thread consumption, lockstitches of class 300, geometrical models, multi-linear regression models, input parameters

\section{List of abbreviations}

$a$, needle thread

$a^{\prime}$, second needle thread

$b$, bobbin thread

$e$, thickness of fabric layers

$t$, thickness of fabric

$L$, stitch length

$S P C$, stitches per centimeter

$d$, sewing thread diameter

$C_{301}$, thread consumption per centimeter of lockstitch type 301

$C_{301 / 301}$ : thread consumption per centimeter of lockstitch type $301 / 301$
$C_{304,308,315}$, thread consumption per centimeter of lockstitch type 304,308 , or 315

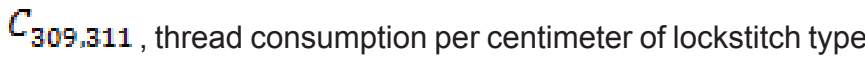
309 or 311

$C_{310,312}$, thread consumption per centimeter of lockstitch type 310 or 312

$Y$, yarn linear density in tex

$I$, thread consumed in interlacing with same needle and bobbin thread

$I_{a}$, thread consumed in interlacing with needle thread

$I_{b}$, thread consumed in interlacing with same needle thread

$X$, seam width expressed in centimeter

$X_{1}$, gap between two needles expressed in centimeter 
$C_{T h}$, theoretical value of thread consumption

$C_{E x p}$, experimental value of thread consumption

$\hat{v}_{i}$, vector of the expected values of the response

$v_{i}$, vector of the observed values of the response

$\bar{v}$, average value of the answer

\section{Introduction}

Sewing thread as an important component of a sewn garment contributes significantly to the quality of clothes. An important consideration in selecting thread, other than its performance and its appearance, is the cost of sewing steps of clothes. In fact, the total thread costs include the costs of the thread that is actually used in the production of garments. Besides, the thread that is wasted during the sewing process and the thread stock that remains unused at the end of an order greatly affect the cost of sewing. Therefore, it is important to determine exactly the sewing thread consumption value by indicating the suitable thread quantities which should be available to manufacture garments. This can probably avoid unused stocks and helps industrialists to order suitable quantities of thread before starting the sewing process.

According to the literature, the determination of thread consumption depends on several parameters. First, thread consumption varies not only between different types of garments but also between garments of the same class. Differences in size, style, and material of the garment determine the amount of thread used. Second, thread consumption is also related directly to stitch length, stitch density, seam type, thread tension, fabric compressibility, and its compressive modulus [1]. Other influential factors, which can extremely affect thread consumption during the sewing steps, have not been studied yet. Indeed, few investigations have been done to determine the impact of sewing machine parameters, thread insertion method, and garment model on the consumed thread [2, 3, 4]. It is very complicated to optimize all effective parameters during the sewing steps. Therefore, the consumed thread was generally estimated based on approximations and presumptions especially when seam type, stitch density, and material thickness were the main studied input parameters [4, 5]. Based on the literature review, some studies using different methods have been proposed dealing with consumption problem of the sewing thread based on different basic stitch types. Abher et al., Gazzah et al., Ghosh \& Chavhan, and Jaouadi et al. considered geometrical models to calculate the consumption of sewing thread for 301 lockstitch, 504 over-edge stitch, and cover stitch type 602 as a function of different parameters such as stitch length, stitch density, material thickness, sewing thread thickness, and interlacing [1, 2, 6-8]. Jaouachi et al. provided a rapid and accurate method to predict the amount of sewing thread required to stitch a specific length of woven fabric using lockstitch (301) and chain stitch (401) [9]. Hence, to attempt his goal, the effect of stitches/cm, number of assembly layers and fabric thickness, the fabric mass parameter and the fabric composition, the sewing machine type, the sewing thread count, and the size of needle (fineness or needle count) on the sewing thread consumption values has been studied $[10,9,11]$. In this context, some studies have been carried out. Abher et al. considered the geometrical model to calculate the consumption of sewing thread for 301 lockstitch and 504 overedge stitch [2,6]. Jaouachi et al. provided a rapid and accurate method to predict the amount of sewing thread required to stitch a specific length of woven fabric using lockstitch (301) and chain stitch (401) [10].

Moreover, lockstitch type 301 was studied by Khedher and Jaouachi [12]. Jaouadi et al. compared thread consumption using both regression analysis and neural network. They proved that the neural network gives the most accurate prediction [8]. Recently, in order to predict the sewing consumption, Gazzah et al. developed a model, based on 602 geometrical cover stitches, to calculate the relative consumed sewing thread length [7].

Although the prediction of thread consumption has been studied for $301,401,504,516$, and 602 stitches, until now no work dealing with the correlation between all types of stitch in the same class has been considered. The purpose of this study is to accurately determine the amount of sewing thread required to stitch a specific length of woven fabric using all different lockstitch types of class 300 (301, 301/301, 304, 308, 309, 311, 310,312 , and 315). Indeed, two methods are proposed and compared to select the best one for the prediction of thread consumption and help industrialists to evaluate accurately the consumed amount of sewing threads. Thus, the geometrical method consists in determining a relationship between thread consumption of 301 lockstitch and the other stitch types of class 300 and a multi-linear regression method. Moreover, the effect of each input parameter is studied and discussed to clarify industrialists about the most significant factors to regulate before launching production.

\section{Materials and methods}

\subsection{Fabric properties}

Six commercial denim fabrics having different thicknesses and blend compositions were chosen in our study. These samples with their characteristics are summarized in Table 1 and are chosen to cover a large thickness range.

The six studied denim fabrics were prepared on a SULZER P7300 weaving loom projectile with $3 / 1$ twill structure. Knowing that denim fabrics are generally made of cotton, cotton/elastane, or cotton/polyester/elastane, these specific compositions are considered in this work.

Based on Standard EN 1049-2, the warp and weft yarn densities were determined [13]. The mass of the studied specimens was calculated according to EN 12127 [14]. However, the sample thickness was determined referring to ISO 5084: 1996 [15]. In addition, tensile behavior of the denim fabric such as breaking 
Table 1. Fabric properties.

\begin{tabular}{|c|c|c|c|c|c|c|c|c|c|}
\hline \multirow{2}{*}{$\begin{array}{c}\text { Parameter } \\
\text { Fabric } \\
\text { composition } \\
\text { no. }\end{array}$} & \multirow[b]{2}{*}{$\begin{array}{l}\text { Warp yarn } \\
\text { density } \\
\text { (ends/cm) }\end{array}$} & \multirow[b]{2}{*}{$\begin{array}{l}\text { Weft yarn } \\
\text { density } \\
\text { (picks/cm) }\end{array}$} & \multicolumn{2}{|c|}{ Mass } & \multicolumn{2}{|c|}{ Thickness } & \multicolumn{3}{|c|}{ Tensile properties } \\
\hline & & & $\begin{array}{l}\text { Mass } \\
\left(\mathrm{g} / \mathrm{m}^{2}\right)\end{array}$ & $\begin{array}{l}\text { CV } \\
(\%)\end{array}$ & $\begin{array}{l}\text { Thickness } \\
\text { (mm) }\end{array}$ & $\begin{array}{l}\text { CV } \\
(\%)\end{array}$ & $\begin{array}{l}\text { Breaking } \\
\text { strength } \\
\text { (N) }\end{array}$ & $\begin{array}{l}\text { Elongation } \\
\text { at break (\%) }\end{array}$ & CV (\%) \\
\hline \multirow{2}{*}{$1^{*}$} & 26 & 17 & 323 & 1.9 & 1.2 & 1.4 & 413.63 & 12.66 & 1.4 \\
\hline & 30 & 22 & 387 & 2.1 & 1.04 & 1 & 1071.90 & 17.89 & 2.1 \\
\hline \multirow{2}{*}{$2^{*}$} & 32 & 17 & 445 & 1.5 & 0.96 & 1.4 & 894.26 & 17.40 & 0.8 \\
\hline & 29 & 22 & 342 & 1.2 & 0.90 & 1.6 & 624.21 & 30.45 & 1.2 \\
\hline \multirow{2}{*}{$3^{*}$} & 31 & 21 & 334 & 1.6 & 0.85 & 1.2 & 557.24 & 33.64 & 0.6 \\
\hline & 28 & 22 & 328 & 0.9 & 0.75 & 2.1 & 528.13 & 25.12 & 2.4 \\
\hline
\end{tabular}

${ }^{*}$ Composition 1: $100 \%$ cotton warp and weft threads. Composition 2: $100 \%$ cotton warp yarn and weft yarn in $95 \%$ cotton and $5 \%$ elastane. Composition 3: $100 \%$ cotton warp yarn and weft yarn in $71 \%$ cotton, $5 \%$ elastane, and $24 \%$ polyester.

strength and the elongation at break was investigated applying ISO 13934-1 [16].

\subsection{Sewing thread properties}

Two commercial threads, commonly used for sewing denim fabrics, were selected. The choice of these threads was based on their linear densities which can probably affect the used amount of sewing thread. It is notable that, for these sewing threads, mercerizing and bleaching pretreatments were applied. To conduct accurately our study, the sewing thread linear densities were chosen according to NFG 07-117 [3]. Table 2 summarizes the seam threads' properties.

\subsection{Methods used for thread consumption prediction}

Two methods are considered: a geometrical method and a multi-linear regression method. In fact, nine types of stitch for class 300 were considered. They are usually used for sewing denim garments such as trousers, shirts, jacket, etc. These stitches are as follows:

1. Lockstitch 301

2. Parallel lockstitch $301 / 301$

3. Zigzag lockstitch 304

4. Two-step zigzag lockstitch 308

5. Three-thread lockstitch 309

Table 2. Sewing thread properties.

\begin{tabular}{|c|c|c|}
\hline Properties & Thread no. 1 & Thread no. 2 \\
\hline Linear density (tex) & 63.50 & 95.00 \\
\hline Number of strands & 3 & 3 \\
\hline Composition & $100 \%$ PES & $100 \%$ PES \\
\hline Twist direction & S & S \\
\hline Breaking strength (N) & 24.23 & 26.43 \\
\hline Breaking elongation (\%) & 21.12 & 16.90 \\
\hline Rigidity (N/m) & 389.12 & 536.59 \\
\hline Twist/m & 353.00 & 294.00 \\
\hline Tenacity (cN/tex) & 38.16 & 27.82 \\
\hline
\end{tabular}

\section{Three-thread lockstitch 310 \\ 7. Three-thread lockstitch 311 \\ 8. Three-thread lockstitch 312 \\ 9. Three-step zigzag lockstitch 315}

Nevertheless, for the multi-linear regression, a statistical method based on experimental design using MINITAB-17 software was applied to conduct objectively this modeling technique. Moreover, based on this multi-linear regression model, thanks to MINITAB-17 software, individual effects of input parameter were determined, analyzed, and classified. For both geometrical and statistical methods, five input parameters with their levels were taken into account (fabric thickness [6 levels], stitch density [3 levels], yarn count [2 levels], stitch width [3 levels], and the gap between two needles [2 levels]). It is highly complicated to optimize all effective parameters during the sewing process. The predictive thread consumption is still related to the stitched fabric plies or layers. In this work, it is shown that all samples were sewed using two fabric plies.

\section{Results and discussion}

\subsection{Geometrical model}

Case of lockstitch type 301

Based on its stitch shape, the consumption of lockstitch type 301 as well as the other types of class 300 was considered.

Using Profile Projector and Projection Microscope, it was confirmed that the shape of lockstitch is rectangular [2]. Figure 1a shows the geometrical shape of the lockstitch type 301. A single stitch, as presented in Figure $1 \mathrm{~b}$, consists of a rectanaular shape and interlacing of bobbin $(a)$ and needle threads $(b)$.

Thus, sewing thread consumed to make a single stitch can be calculated by using Equation (1) [2].

$$
C_{301}=\operatorname{SPC}(2(L+e)+I)
$$

In our case, the "thickness of fabric lavers" $(e)$ is equal to twice the value of the fabric thickness $(t)$. 
A

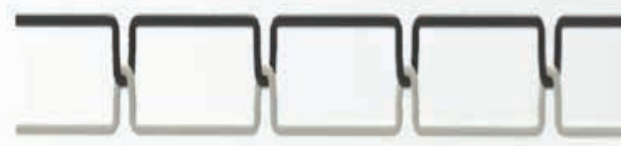

B

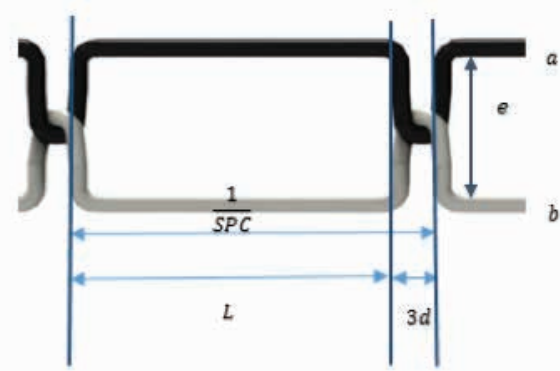

Figure 1. Lockstitch type 301 geometry (a) and lockstitch (301) components within geometrical parameters (b).

As shown in Figure 2, the stitch length can be calculated according to Equation (2) [2];

$L=\left(\frac{1}{S P C}\right)-(3 d)$

To calculate the sewing thread diameter supposed as circular $(d)$, we used the general equation supposed by Sohanur [17] as a function of the thread linear density Y (Equation 3).

$d(\mathrm{~cm})=\frac{0.375}{100} \sqrt{\mathrm{Y}}$

The consumed interlacing thread must be studied to determine the exact value of this variable. Figure 2 shows the interlacing point of 301 lockstitch.

For same needle and bobbin thread, as shown in Figure 2, we note Equation 4:

$I_{a}=I_{b}=\pi r$

Or in our case, $r=d+\frac{d}{2}$

The interlacing of the same needle and bobbin thread type is equal to I (Equation 6)

$I=I_{a}+I_{b}=2 \pi\left(d+\frac{d}{2}\right)$

Thus, based on Equation 6, the consumed interlacing thread was calculated as presented in Equation 7.

$\mathrm{I}=2 \pi \frac{3}{2} \times \frac{0.375}{100} \sqrt{\mathrm{Y}}=3.53 \times 10^{-2} \sqrt{\mathrm{Y}}$

So, the lockstitch 301 thread consumed was calculated based on Equation 8.

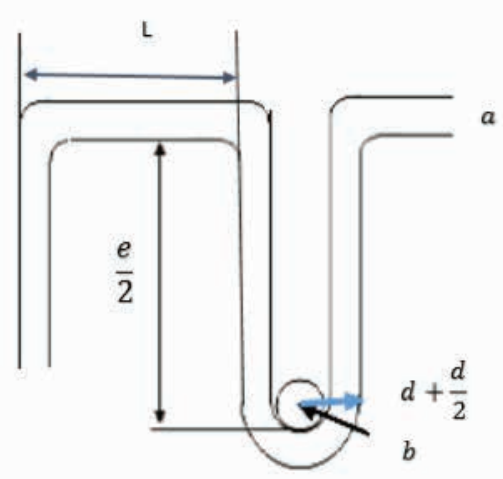

Figure 2. Interlacing point of 301 lockstitch.
$\left.C_{301}=\operatorname{SPC}\left(2\left(\left(\frac{1}{S P C}\right)-\left(3\left(\frac{0.375}{100}\right) \sqrt{\mathrm{Y}}\right)\right)+e\right)+\left(3.53 * 10^{-2} \sqrt{\mathrm{Y}}\right)\right)(8)$

According to the other stitch types of class 300 , the consumption will be derived from Equation 8.

Case of lockstitch type 301/301

Seeing that lockstitch type $301 / 301$ (Figure 3) is a double lockstitch type 301 , the thread consumption will be equal to double the thread consumption value of lockstitch type 301. Thus, the thread consumption of this type of lockstitch is presented in Equation 9.

$C_{301 / 301}=2 * C_{301}=2 * \operatorname{SPC}\left(2\left(\left(\frac{1}{S P C}\right)-\left(3\left(\frac{0.375}{100}\right) \sqrt{\mathrm{Y}}\right)\right)+e\right)+\left(3.53 * 10^{-2} \sqrt{\mathrm{Y}}\right)(9)$

Case of lockstitch types 304, 308, and 315

According to 304,308 , and 315 lockstitches, the stitch types composed of a needle and bobbin threads forming a symmetrical zigzag pattern. Figure 4 shows the geometrical presentations of these stitches.

$C_{304,308,315}=\operatorname{SPC}(2(L+\mathrm{e})+\mathrm{I})$

Supposing that $L^{\prime}=L+3 d$

As $L^{\prime 2}=\left(\frac{1}{S P C}\right)^{2}+X^{2}$

$\rightarrow L^{\prime}=\sqrt{\left(\frac{1}{S P C}\right)^{2}+X^{2}}$

$\rightarrow L=\sqrt{\left(\frac{1}{S P C}\right)^{2}+X^{2}}-3 d$

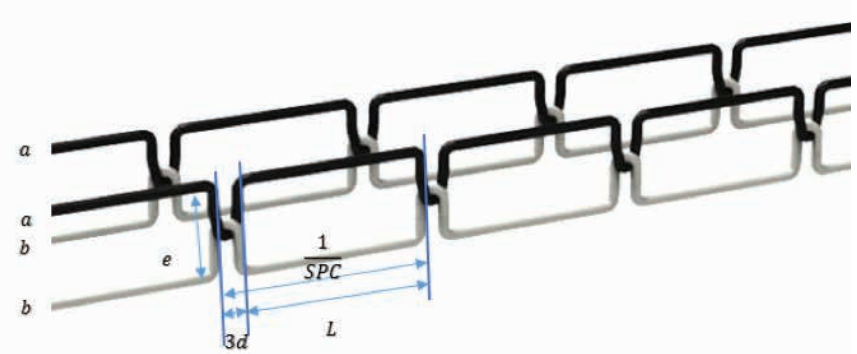

Figure 3. Geometrical model of lockstitch type 301/301 


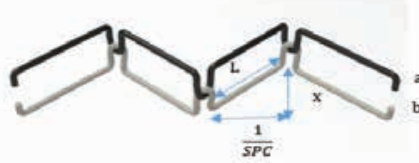

(a)

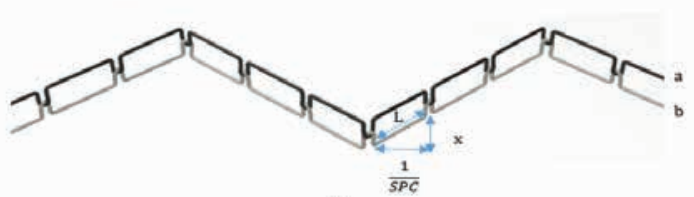

(c)

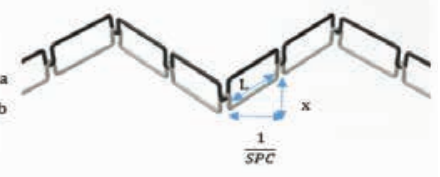

(b)
Figure 4. Geometrical models of lockstitch types 304 (a), 308 (b), and 315(c).

Thus, the thread consumption was as follows:

$\left.\rightarrow C_{304,308,315}=\operatorname{SPC}\left(2\left(\sqrt{\left(\frac{1}{S P C}\right)^{2}+X^{2}}-3 d\right)+e\right)+I\right)$

$\rightarrow C_{304,308,315}=\operatorname{SPC}\left(2\left(\left(\sqrt{\left(\frac{1}{S P C}\right)^{2}+X^{2}}-3 d\right)+\mathrm{e}\right)+I\right)$

\section{Cases of lockstitch types 309 and 311}

The type of stitches is simple stitching at the lockstitch, two needles, and three threads. Figure 5 shows the geometrical presentation of stitch types 309 (Figure 5a) and 311 (Figure $5 b)$.

As shown in Figure 5, we concluded the Equation 17.

$X_{2}=\sqrt{\left(L^{2}+X_{1}{ }^{2}\right)}$

$C_{309,311}=\operatorname{SPC}\left((2(L+2 e)+2 I)+\left(X_{1}+X_{2}\right)\right)$

$$
\left.C_{309,311}=\operatorname{SPC}\left(\left(2\left(\left(\frac{1}{S P C}\right)-3 d\right)+2 e\right)+2 I\right)+\left(X_{1}+\sqrt{\left(\left(\frac{1}{S P C}\right)-3 d\right)^{2}+X_{1}^{2}}\right)\right)
$$

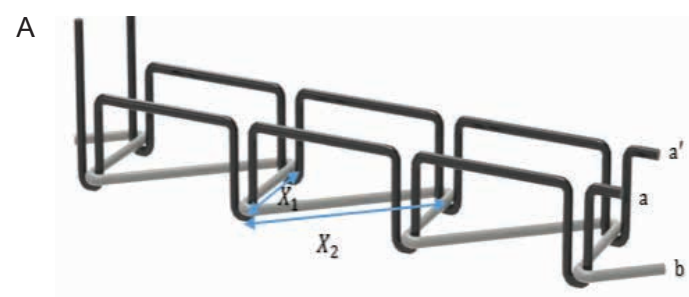

Figure 5. Geometrical models of lockstitch types 309 (a) and 311 (b).

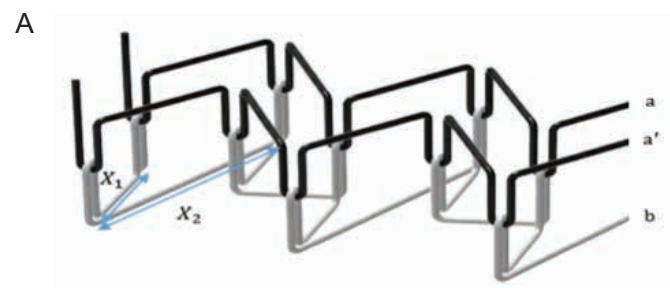

Figure 6. Geometrical models of 310 (a) and 312 lockstitches (b).

\section{Cases of lockstitch types 310 and 312}

The type of stitches is simple stitching at the lockstitch, two needles, and three threads such as lockstitch types 309 and 311 , respectively, except that these types of stitch form a symmetrical zigzag pattern. Figure 6 shows the geometrical presentation of lockstitch types 310 (Figure 6a) and 312 (Figure 6b).

The thread consumption for lockstitch types 310 and 312 is presented in Equation 20.

$\left.\left.C_{310,312}=\operatorname{SPC}\left(\left(2\left(L^{\prime}-3 d\right)+2 e\right)+2 I\right)+\left(X_{1}+\sqrt{\left(L^{\prime}-3 d\right)^{2}+X_{1}^{2}}\right)\right)\right)$

where $L^{\prime}=\sqrt{\left(\left(\frac{1}{S P C}\right)^{2}+X_{1}^{2}\right.}$

Correlation of geometrical models based on 301 geometrical model

To conclude, the following equations present the relationship between thread consumption for each stitch type of class 300 based on 301 lockstitch:

$$
\begin{aligned}
& \left.C_{301}=S P C\left(2\left(\left(\frac{1}{S P C}\right)-(3 d)\right)+e\right)+I\right) \\
& C_{301 / 301}=2 * C_{301} \\
& \left.C_{304,308,315}=C_{301}-S P C \times 2\left(\frac{1}{S P C}-3 d\right)+S P C * 2 * \sqrt{\left(\frac{1}{S P C}\right)^{2}-X^{2}}-3 d\right) \\
& =C_{301}-2 \times S P C\left(\left(\frac{1}{S P C}-3 d\right)-\left(\sqrt{\left.\left.\left(\frac{1}{S P C}\right)^{2}+X^{2}-3 d\right)\right)}\right.\right. \\
& =C_{301}-2 \times S P C\left(\frac{1}{S P C}+\sqrt{\left(\frac{1}{S P C}\right)^{2}-X^{2}}\right) \\
& \left.=C_{301}-2+2 S P C \sqrt{\left(\frac{1}{C D C}\right)^{2}+X^{2}}\right) \\
& C_{309,311}=S P C\left((2(L+2 e)+2 I)+\left(X_{1}+X_{2}\right)\right) \\
& =C_{301}-S P C\left(2 e+I+\left(X_{1}+X_{2}\right)\right.
\end{aligned}
$$

B

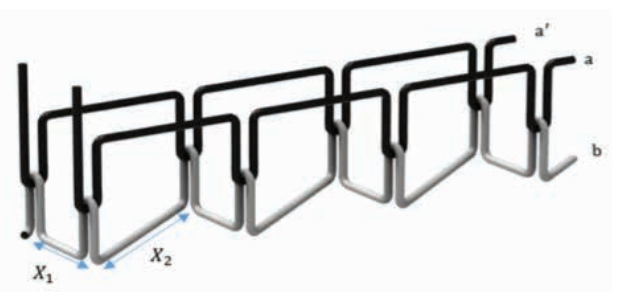

B

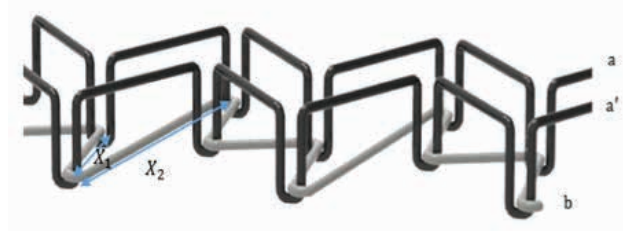


$=C_{301}-\operatorname{SPC}\left(2 e+I+\left(X_{1}+\sqrt{\left.\left.\left(\frac{1}{S P C}\right)+3 d\right)\right)}\right.\right.$

$C_{310,312}=S P C\left(\left(2\left(\sqrt{\left(\left(\frac{1}{S P C}\right)^{2}+X_{1}{ }^{2}\right.}-3 d+2 e\right)+2 I\right)+\right.$

$+\sqrt{\left.\left.\left.\left(\sqrt{\left(\left(\frac{1}{S P C}\right)^{2}+X_{1}^{2}\right.}-3 d\right)^{2}+X_{1}^{2}\right)\right)\right)}$

$=C_{301}-2+\operatorname{SPC}\left(2 \sqrt{\left(\left(\frac{1}{S P C}\right)^{2}+X_{1}^{2}\right.}+2 e+I+X_{1}+X_{2}\right.$

In order to verify these models, 36 samples were prepared by varying the different factors for $(301,301 / 301)$ lockstitches, 108 samples were prepared for $(304,308,315)$ lockstitches, and 72 samples for $(309,310)$ and $(310,312)$ lockstitches. Table 3 summarizes the different factors and levels for each type of lockstitch point.

Table 4 summarizes the levels of each factor for preparing the samples of each type of lockstitch of class 300 .

Samples were prepared, and $10 \mathrm{~cm}$ seam length of each sample was chosen and investigated. Then, the seam was unstitched to get the needle and bobbin thread consumed in $5 \mathrm{~cm}$ length. After unstitching, the sewed thread length was determined to measure the value of the consumed thread per centimeter.

Table 3. Different factors for each type of lockstitch.

\begin{tabular}{|c|c|c|c|c|c|}
\hline Lockstitches & $\varepsilon$ & $S P C$ & $Y$ & $X$ & $X_{1}$ \\
\hline 301 & $*$ & $*$ & $*$ & & \\
\hline $301 / 301$ & $*$ & $*$ & $*$ & & \\
\hline $304 / 308 / 315$ & $*$ & $*$ & $*$ & $*$ & \\
\hline $309 / 310$ & $*$ & $*$ & $*$ & & $*$ \\
\hline $310 / 312$ & $*$ & $*$ & $*$ & & $*$ \\
\hline
\end{tabular}

${ }^{*}$ Represents the existent parameter for each studied lockstitch type.

Table 4. Levels of each factor.

\begin{tabular}{|c|c|c|c|c|c|}
\hline $\begin{array}{c}\text { Input } \\
\text { parameter }\end{array}$ & $\begin{array}{c}e \\
(\mathrm{~cm})\end{array}$ & $\begin{array}{c}S P C \\
\text { (stitches/ } \\
\mathrm{cm} \text { ) }\end{array}$ & $\begin{array}{c}Y \\
\text { (tex) }\end{array}$ & $\begin{array}{c}X \\
(\mathrm{~cm})\end{array}$ & $\begin{array}{c}X_{1} \\
(\mathrm{~cm})\end{array}$ \\
\hline Level 1 & 0.120 & 3 & 63.5 & 0.2 & 0.48 \\
\hline Level 2 & 0.104 & 4 & 95 & 0.4 & 0.65 \\
\hline Level 3 & 0.096 & 5 & - & 0.8 & - \\
\hline Level 4 & 0.090 & - & - & - & - \\
\hline Level 5 & 0.085 & - & - & - & - \\
\hline Level 6 & 0.075 & - & - & - & - \\
\hline
\end{tabular}

Table 5. Compared experimental and theoretical results for 301 .

\begin{tabular}{|c|c|c|c|c|c|}
\hline${ }^{t}(\mathrm{~cm})$ & $\begin{array}{c}S P C \\
\text { (stitches/ } \\
\mathrm{cm} \text { ) }\end{array}$ & $Y_{\text {(tex) }}$ & $C_{E x p}(\mathrm{~cm})$ & $C_{T h(\mathrm{~cm})}$ & CV (\%) \\
\hline 0.120 & 3 & 63.5 & 3.920 & 3.746 & 0.2 \\
\hline 0.104 & 3 & 63.5 & 3.724 & 3.554 & 0.5 \\
\hline 0.096 & 3 & 63.5 & 3.476 & 3.458 & 0.2 \\
\hline 0.090 & 3 & 63.5 & 3.440 & 3.386 & 0.5 \\
\hline 0.085 & 3 & 63.5 & 3.410 & 3.326 & 0.3 \\
\hline 0.075 & 3 & 63.5 & 3.350 & 3.206 & 0.2 \\
\hline 0.120 & 4 & 63.5 & 4.460 & 4.328 & 0.4 \\
\hline 0.104 & 4 & 63.5 & 4.132 & 4.072 & 0.4 \\
\hline 0.096 & 4 & 63.5 & 4.068 & 3.944 & 0.2 \\
\hline 0.090 & 4 & 63.5 & 3.920 & 3.848 & 0.3 \\
\hline 0.085 & 4 & 63.5 & 3.680 & 3.768 & 0.5 \\
\hline 0.075 & 4 & 63.5 & 3.600 & 3.608 & 0.1 \\
\hline 0.120 & 5 & 63.5 & 4.800 & 4.910 & 0.2 \\
\hline 0.104 & 5 & 63.5 & 4.440 & 4.590 & 0.4 \\
\hline 0.096 & 5 & 63.5 & 4.460 & 4.430 & 0.5 \\
\hline 0.090 & 5 & 63.5 & 4.400 & 4.310 & 0.3 \\
\hline 0.085 & 5 & 63.5 & 4.350 & 4.210 & 0.1 \\
\hline 0.075 & 5 & 63.5 & 3.950 & 4.010 & 0.2 \\
\hline 0.120 & 3 & 95.0 & 3.720 & 3.814 & 0.4 \\
\hline 0.104 & 3 & 95.0 & 3.624 & 3.622 & 0.5 \\
\hline 0.096 & 3 & 95.0 & 3.576 & 3.526 & 0.5 \\
\hline 0.090 & 3 & 95.0 & 3.540 & 3.454 & 0.4 \\
\hline 0.085 & 3 & 95.0 & 3.510 & 3.394 & 0.4 \\
\hline 0.075 & 3 & 95.0 & 3.450 & 3.274 & 0.3 \\
\hline 0.120 & 4 & 95.0 & 4.460 & 4.419 & 0.4 \\
\hline 0.104 & 4 & 95.0 & 4.232 & 4.163 & 0.5 \\
\hline 0.096 & 4 & 95.0 & 3.968 & 4.035 & 0.5 \\
\hline 0.090 & 4 & 95.0 & 4.020 & 3.939 & 0.4 \\
\hline 0.085 & 4 & 95.0 & 3.880 & 3.859 & 0.2 \\
\hline 0.075 & 4 & 95.0 & 3.600 & 3.699 & 0.4 \\
\hline 0.120 & 5 & 95.0 & 5.000 & 5.024 & 0.5 \\
\hline 0.104 & 5 & 95.0 & 4.640 & 4.704 & 0.2 \\
\hline 0.096 & 5 & 95.0 & 4.460 & 4.544 & 0.5 \\
\hline 0.090 & 5 & 95.0 & 4.400 & 4.424 & 0.2 \\
\hline 0.085 & 5 & 95.0 & 4.350 & 4.324 & 0.2 \\
\hline 0.075 & 5 & 95.0 & 4.150 & 4.124 & 0.3 \\
\hline
\end{tabular}


Table 5 summarizes the comparison between the experimental $\left(C_{E x p}\right)$ and the theoretical $\left(C_{T h}\right)$ thread consumptions within their absolute errors based on the lockstitch type 301 .

To improve the obtained results, the average absolute relative error, $\overline{\text { Error }}$ (Equation 27) between the theoretical ( $C_{T h}$ ) and experimental values $\left(C_{E x p}\right)$ was determined. The limit of the mean absolute error values used in the modeling is estimated to be $6 \%$ [18].

$\overline{\text { Error }}=\frac{\left|C_{T h}-C_{E x p}\right|}{C_{E x p}} * 100$

Table 6 summarizes the average error for each type of lockstitch of class 300 .

Table 6. Average error.

\begin{tabular}{|c|c|c|c|c|c|}
\hline Stitch & $\mathbf{3 0 1}$ & $\mathbf{3 0 1 / 3 0 1}$ & $\mathbf{3 0 4}$ & $\mathbf{3 1 1}$ & $\mathbf{3 1 0}$ \\
\hline$\overline{\text { Error }(\%)}$ & 2.02 & 2.39 & 3.04 & 3.76 & 3.85 \\
\hline
\end{tabular}

The average absolute error does not exceed $3.85 \%$. Thus, the result of testing thread consumption is verified widely. In fact, regarding the findings, the error values are much lower than $6 \%$. Thus, the studied models are well justified and the findings are highly significant.

Compared experimental and theoretical values showed good agreement between geometrical and experimental consumption values. Indeed, the coefficient of regression ranged from $93.91 \%$ to $99.10 \%$ (Figures $7-12$ ), which reflects significant and efficient relationships between experimental and theoretical findings. The low difference between geometrical and experimental results can be explained by the presumptions used to facilitate theoretical calculation of the obtained model such that the same yarn section is circular and incompressible; the diameters of needle and bobbin thread are equal (are considered equal to yarn present in a given fabric) and the fabric samples are also considered as incompressible.

Regarding that the error rate is very low and the regression coefficients values are very high (from $93.91 \%$ to $99.10 \%$ ), it was concluded that the obtained geometrical models are fruitful and could be recommended for the prediction of thread consumption in the experimental design of interest.

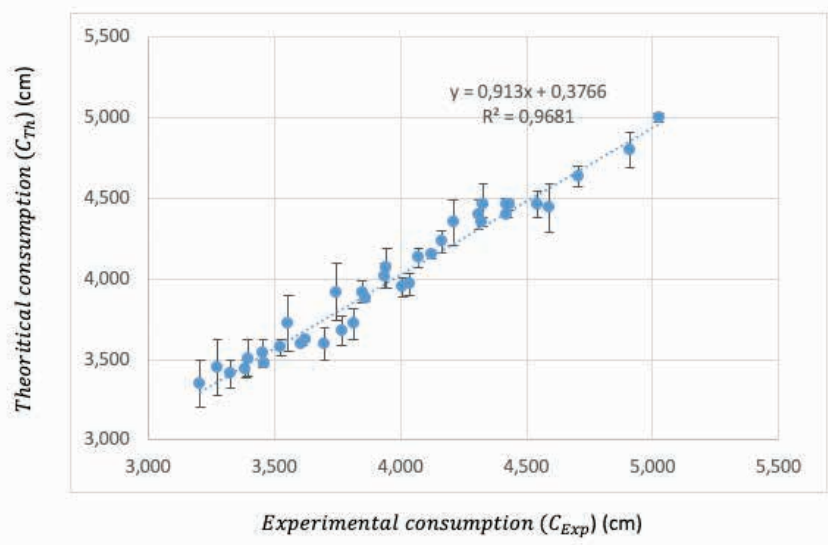

Figure 7. Theoretical consumption evolution as a function of experimental results for lockstitch type 301.

\subsection{Multi-linear regression models}

Multi-linear regression method was applied to compare its results with those obtained using geometrical method. The comparison can help industrialists to use the best method to predict the consumed thread to sew denim garments.

A statistical method based on experimental design was applied to study the effect of each investigated input parameter and accurately estimate the suitable amount of thread based on different lockstitch types. Indeed, thanks to MINITAB-17

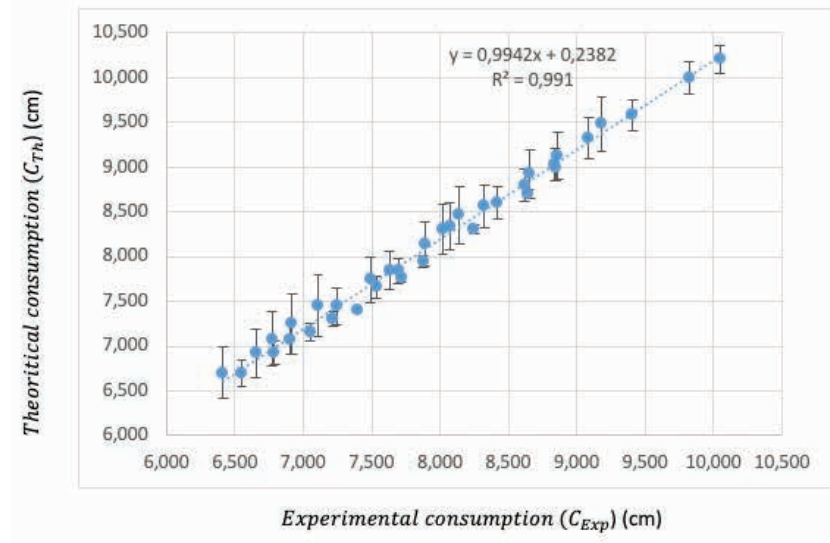

Figure 8. Theoretical consumption evolution as a function of experimental results for lockstitch type 301/301.

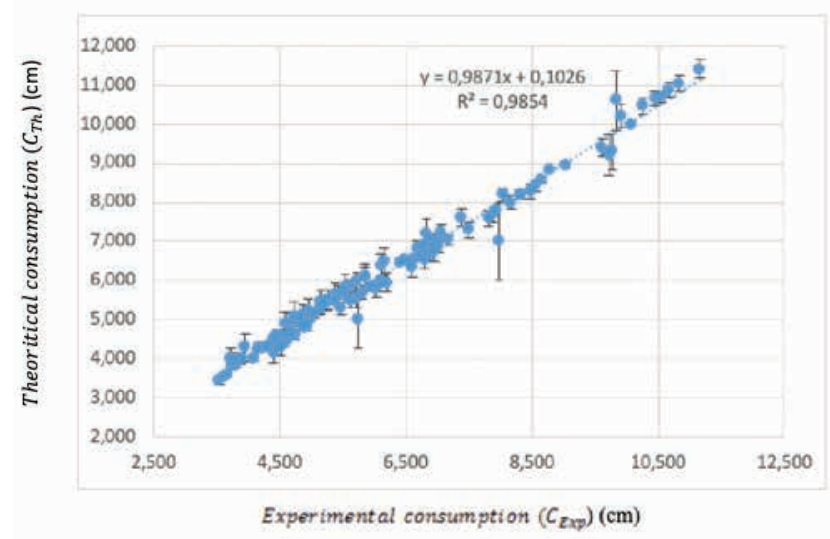

Figure 9. Theoretical consumption evolution as a function of experimental findings for lockstitch types 304, 308, and 311.

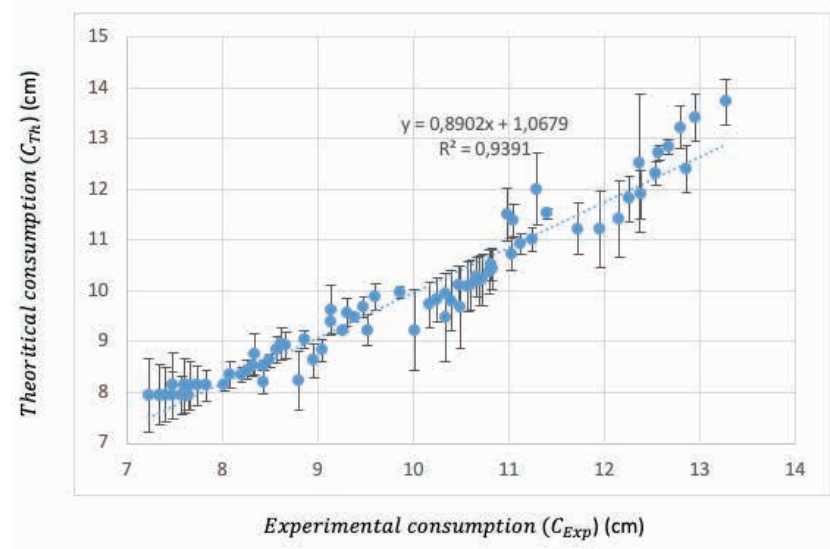

Figure 10. Theoretical consumption evolution as a function of experimental findings for lockstitch types 309 and 315. 


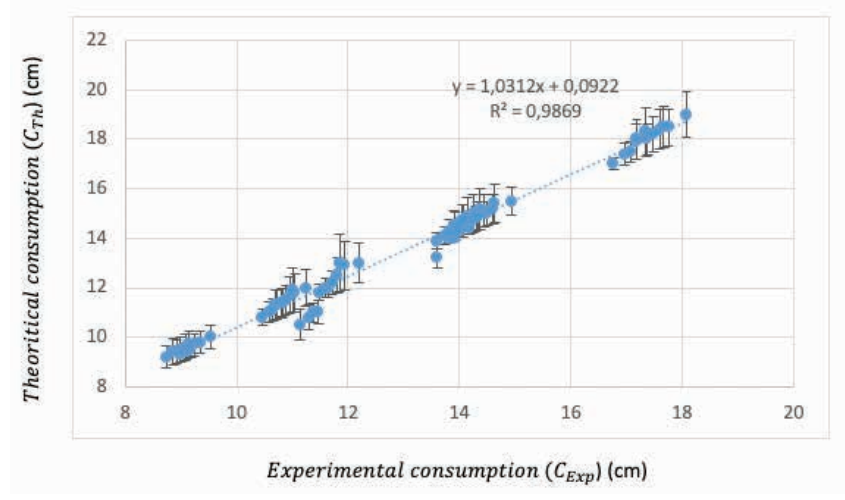

Figure 11. Theoretical consumption evolution as a function of experimental findings for lockstitch types 310 and 312 .

software, the multi-linear regression models were determined. The individual effects of each input parameter are analyzed. Tables 3 and 4 present the studied input parameters as well as their levels. The findings for lockstitch types 304, 308, and 315 have the same geometrical equation. Besides, for the lockstitch types $(309,311)$ and $(310,312)$, they have the same equation, which means that multi-linear regression models concern each group of stitches mentioned above. Hence, five different models are considered as summarized in Table 7.

The value of regression coefficient $R^{2}$ reflects the significance and relevance of the developed models. Indeed, this coefficient of regression (Equation 28) ranged from 0 to $100 \%$. The closer it is to $100 \%$, the more significant the model is and vice versa [10].

$R^{2}=1-\frac{S S_{\text {error }}}{S S T}=1-\frac{S S_{r e g}}{S S T}$ where

$S S_{\text {error }}$ : The portion of the variation which not explained by the model and is attributed to error. It calculated according to Equation 29:

$S S_{\text {error }}=\sum\left(v_{i}-\hat{v}\right)^{2}$

$S S_{\text {error }}$ : The portion explained by the multi-linear regression model. To calculate it, we used this formula given by Equation 30:

$$
S S_{r e g}=\sum\left(\hat{v}_{i}-\bar{v}\right)^{2}
$$

SST: The sum of squared distances represents the total variation in the experimental data according to these relationships (Equations 31):

$$
S S T=S S_{\text {reg }}+S S_{\text {error }}
$$

Nevertheless, it is important to analyze the statistical analysis variance. Based on the $p$-value of statistical coefficient, it is possible to evaluate the importance of different parameters. In fact, three conditions are presented:

- $\quad p$-value is null: very significant parameter

- $p$-value is ranged from 0 to 0.05 : significant parameter

- $\quad p$-value is higher than 0.05: negligible parameter.

Table 8 summarizes the p-values for each multi-linear regression model.

Table 7. Multi-linear regression models for different lockstitches class 300.

\begin{tabular}{|c|c|}
\hline Equation & $\boldsymbol{R}^{\mathbf{2}(\%)}$ \\
\hline$C_{301}=0.626+15.39 \mathrm{e}+0.4442 \mathrm{SD}+0.001764 \mathrm{Y}$ & 94.41 \\
\hline$C_{301 / 301}=0.827+34.21 \mathrm{e}+0.9633 \mathrm{SPC}+0.00265 \mathrm{Y}$ & 97.86 \\
\hline$C_{304.308 .315}=-2.742+17.00 \mathrm{e}+1.2809 \mathrm{SPC}-0.00786 \mathrm{Y}+6.145 \mathrm{X}$ & 92.84 \\
\hline$C_{309.311}=-4.395+27.38 \mathrm{e}+2.0562 \mathrm{SPC}+0.01266 \mathrm{Y}+6.585 \mathrm{X}_{1}$ & 93.23 \\
\hline$C_{310.312}=-13.310+42.77 \mathrm{e}+3.2892 \mathrm{SPC}+0.01786 \mathrm{Y}+16.791 \mathrm{X}_{1}$ & 97.87 \\
\hline
\end{tabular}

Table 8. $p$-value for each studied model.

\begin{tabular}{|c|c|c|c|c|c|}
\hline Parameter & $\boldsymbol{e}$ & $\boldsymbol{S P C}$ & $\boldsymbol{Y}$ & $\boldsymbol{X}$ & - \\
\hline 301 model & 0.000 & 0.000 & 0.085 & - & - \\
\hline $301 / 301$ model & 0.000 & 0.000 & 0.054 & 0.000 & - \\
\hline $\begin{array}{c}\text { 304, 308, 315 } \\
\text { model }\end{array}$ & 0.001 & 0.000 & 0.012 & - & 0.000 \\
\hline 309,311 model & 0.000 & 0.000 & 0.001 & - & 0.000 \\
\hline 310,312 model & 0.000 & 0.000 & 0.000 & - & - \\
\hline
\end{tabular}

- , no value of parameter which should be mentioned. 
Table 9. Final multi-linear regression models for different lockstitches class 300 .

\begin{tabular}{|c|c|}
\hline Multi-linear regression models & $\boldsymbol{R}^{\mathbf{2}(\%)}$ \\
\hline$C_{301}=0.766+15.39 \mathrm{e}+0.4442 \mathrm{SD}$ & 94.28 \\
\hline$C_{301 / 301}=1.036+34.21 \mathrm{e}+0.9633 \mathrm{SPC}$ & 97.75 \\
\hline$C_{304.308 .315}=-2.742+17.00 \mathrm{e}+1.2809 \mathrm{SPC}-0.00786 \mathrm{Y}+6.145 X$ & 92.84 \\
\hline$C_{309.311}=-4.395+27.38 \mathrm{e}+2.0562 \mathrm{SPC}+0.01266 \mathrm{Y}+6.585 X_{1}$ & 93.23 \\
\hline$C_{310.312}=-13.310+42.77 \mathrm{e}+3.2892 \mathrm{SPC}+0.01786 \mathrm{Y}+16.791 X_{1}$ & 97.87 \\
\hline
\end{tabular}

As summarized in Table 8, each parameter having a $p$-value higher than 0.05 is neglected. As a consequence, the new multi-linear regression models are summarized in Table 9.

Considering the range of $R^{2}$ values obtained (from 92.84\% to $97.87 \%$ ), it may be considered as reliable and significant. Therefore, this range of $R^{2}$ shows the effectiveness of the statistical method to determine the suitable consumption value. Otherwise, to predict consumed thread using multi-linear regression models, industrialists can use statistical results for the estimation of the consumed amount. However, compared to geometrical modeling technique, statistical one remained less accurate, powerful, and predictable regarding its range of $R^{2}$.

Effects of input parameters

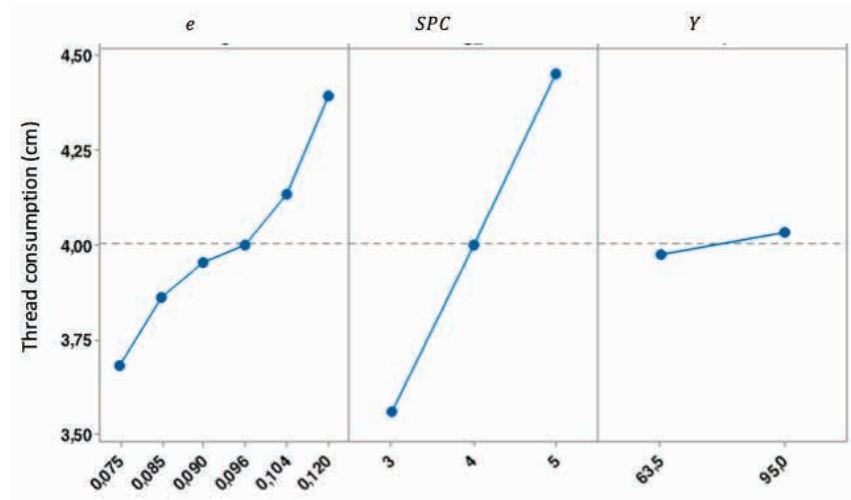

Figure 12. Effects of input parameters for lockstitch type 301.

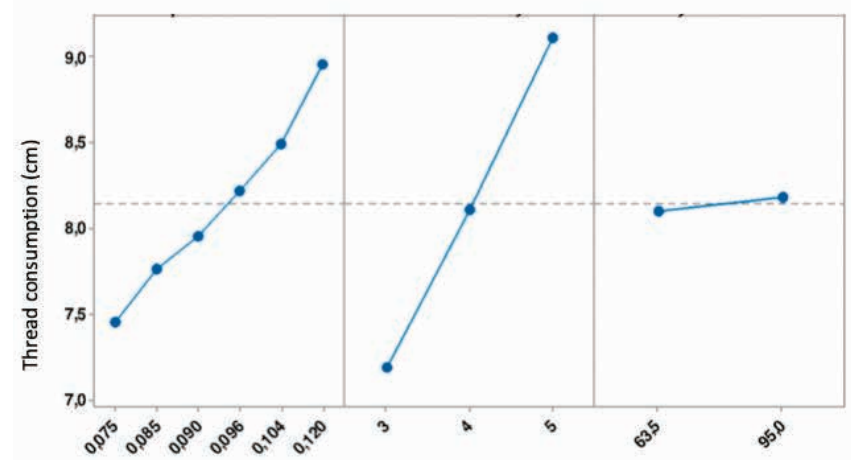

Figure 13. Effects of input parameters for lockstitch type 301.

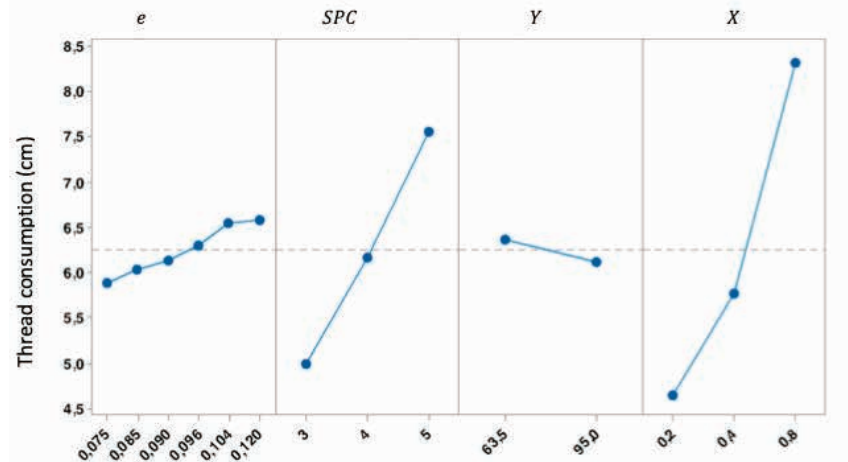

Figure 14. Effects of input parameters for lockstitch types 304, 308, and 315.

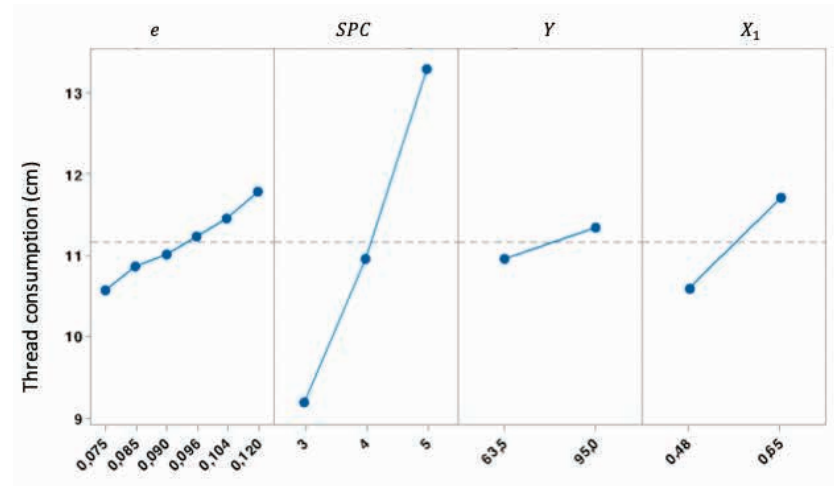

Figure 15. Effects of input parameters for lockstitch types 309 and 311.

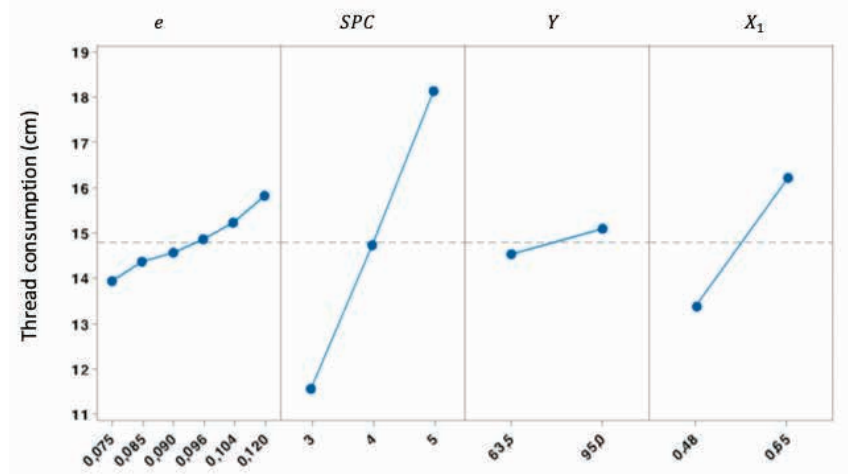

Figure 16. Effects of input parameters for lockstitch types 310 and 312.. 
After determining the regression models, we determined the effect of each input parameter. Figures 12-16 present the influence of fabric thickness, stitch density, yarn linear density, stitch width, and the gap between two needles for different stitches in class 300 .

Fabric thickness effect

As shown in Figures 12-16, we conclude that the increase of fabric thickness from 0.075 to $0.123 \mathrm{~mm}$, increases thread consumption by $19.29 \%, 20.13 \%, 11.90 \%, 11.54 \%$, and $13.62 \%$ for $301,301 / 301,304,309$, and 310 lockstitches, respectively. Thus, fabric thickness remains a significant parameter for three lockstitches. In fact, the increase in fabric thickness increases thread consumption for the five studied lockstitch groups. As the fabric thickness increased, fabric compressibility, compression recovery, and flexural rigidity increased [11]. Although there is a relationship between fabric compressibility of denim samples and the fabric thickness, the thickness has not been considered in the developed geometrical model due to the thickness measurements have been done after the assembly taking into account the different tension and pressure applied during the sewing process. This choice has facilitated the calculation of the consumption value. Indeed, the increase in fabric thickness increases seam thickness as well as thread consumption. Thus, less thick fabric requires less thread, but thicker fabric requires more thread. This result is in accordance with Jaouachi et al. and Abher et al.'s finding that consumption values increase with the increase in fabric thickness. This means that the thickness of fabric samples affects the consumed thread [2, 10]. This finding is also in good agreement with the findings of other researchers $[3,9]$. Besides, according to Jaouachi e al., a heavy fabric consumes more sewing thread than an average fabric. This consumption is estimated of heavy fabrics that are thicker than the average fabrics [9].

Stitch density effect

Stitch density seems an important parameter. In fact, the increase in stitch density from 3 to 5 stitches per centimeter increases the thread consumption percentage of $25 \%, 26.84 \%$, $49.41 \%, 44.83 \%$, and $56.92 \%$ for $301,301 / 301,304,309$, and 310 lockstitches, respectively. Thus, the increase in stitch density increases thread consumption. Besides, the increase in the consumed amount of sewing thread results from the increase in interlacing zone number inside assembled fabric layers. This result is in agreement with the findings of Jaouachi et al., Kennon and Hayes, Hayes, and Abher et al. [2, 9, 19, 20] and confirms our finding that with the fabric feed in motion, the thread is required to form the upper and lower lengths during stitch length modification. Moreover, this result is in agreement with the findings of Lauriol's study [21] which proves that if the sewing length decreases from 2.5 to $2 \mathrm{~mm}$ (4 stitches/cm to 5 stitches/cm), thread consumption increases, approximately, by $10 \%$.

\section{Yarn linear density effect}

Yarn linear density is the parameter that has the lowest impact on thread consumption. Indeed, the increase in yarn linear density from 63.5 to 95 tex increases thread consumption by $1.26 \%, 1.08 \%, 3.56 \%$, and $3.85 \%$ for $301,301 / 301,309$, and 310 lockstitches, respectively. But it decrease by $3.77 \%$ for 304 lockstitch. In fact, in the case of polyester thread composition, the increase in its linear density does not have an important effect on thread consumption. This result is consistent with Jaouachi et al. [9]. In addition, if 100\% PES thread composition is used instead of $100 \%$ cotton yarn, thread consumption becomes much less significant. This may be related to the physical properties of each thread. Besides, this explanation is in total agreement with Lauriol [21] who confirmed that the sewing thread consumption can decrease by $5 \%$ when a continuous polyester yarn is used instead of a cotton thread.

\section{Seam width effect}

As shown in Figure 14, for 304, 308, and 315, stitch width is an important parameter. The increase in the seam width value $(X)$ increases thread consumption. In fact, increasing $X$ from 0.2 to $0.4 \mathrm{~cm}$ and from 0.4 to $0.8 \mathrm{~cm}$, thread consumption increased from 4.65 to $5.76 \mathrm{~cm}$ and from 5.76 to $8.31 \mathrm{~cm}$, respectively (the total percentage increase is equal to $78.71 \%$ ). This is because the increase in width increases the stitch length. This result is confirmed by Goldnfiber who reported that higher width of seam requires more thread to sew the garments [22].

\section{Gap between two needles effect}

As shown in Figures 15 and 16, for $(309,311)$ and $(310,312)$ lockstitches, findings show that the longer the gap between two needles is, the higher thread consumption becomes. The increase in this distance from 0.48 to $0.65 \mathrm{~cm}$, increased thread consumption value by $10.47 \%$ to $21.37 \%$, respectively. This result is well expected; in fact, the increase in the gap between two needles increases $X_{1}$ and $X_{2}$ values, so the thread consumption increases.

\section{Conclusions}

The obtained results reveal that geometrical modeling is an accurate method to predict more precisely the consumed amount of sewing thread using denim samples and lockstitch of class 300 . Besides, to validate the accuracy of the geometrical method, multi-linear regression models were carried out and discussed, showing their significance to evaluate the sewing thread consumption.

Using statistical analysis, multi-linear regression models were obtained and investigated. Their corresponding R2 values ranged from $92.84 \%$ to $97.87 \%$, which demonstrates their accuracy. Seeing that R2 of the geometrical models is more significant (R2 ranged from $93.91 \%$ to $99.10 \%$ ), geometrical models help industrials to sufficiently predict the sewing thread consumption using lockstitch types 301, 301/301, 304, 308, $309,310,311,312$, and 315 . Notwithstanding to select the most influential input parameters on the consumption behavior, a classification of the significance based on p-values is applied. The most important parameters on thread consumption are the stitch width, stitch density, and the gap between two needles. 
Indeed, to decrease the consumption value of sewing thread, industrialists should decrease the value of all these inputs. However, in our experimental setup, the fabric thickness range is between 0.75 and $1.02 \mathrm{~mm}$, these values are very close, that explain the fact that in these condition the thickness has a very low influence on the thread consumption.

\section{References}

[1] Ghosh, S., \& Chavhan, M. V. (2014). Indian Journal of Fibre and Textile Research, 39, 154.

[2] Abher, R., Sheraz, A., Mohsin, M., Ahmad, F., Afzal, A. (2014). Geometrical model to calculate the consumption of sewing thread for 301 lockstitch. Journal of Textile Institute, 105(12), 1261.

[3] Mousazadegan F., Saharkhiz, S., Latifi, M. (2012). Prediction of tension seam pucker formation by finite-element model. International Journal of Clothing Science and Technology, 24(2/3), 129-140.

[4] Ranga Prasad Abeysooriya and Ganemulle Lekamalage Dharmasri Wickramasinghe. (2014). Regression model to predict thread consumption incorporating thread-tension constraint: study on lock-stitch 301 and chain-stitch 401, Abeysooriya and Wickramasinghe Fashion and Textiles, 1-14.

[5] O'Dwyer, U., Munden, D, L. (1975). A study of the lockstitch seam. Part 2. The extension at break of lockstitch seams under longitudinal loading conditions. Clothing Research Journal, 3(1), 33-40.

[6] Abher, R., Sheraz, A., Nauman, A., Ateeq E. R., Muhammad, B. R. (2018). Geometrical model to calculate the consumption of sewing thread for 504 over-edge stitch. The Journal of Textile Institute. https://doi.org/10.1080/004 05000.2018.1423902

[7] Gazzah, M., Khedher, F., Jaouachi, B. (2017). Modelling the sewing thread consumption of 602 cover-stitch based on its geometrical shape. The International Journal of Applied Research on Textile, 5(2).

[8] Jaouadi, M., Msahli, S., Babay, A., Zitouni, B. (2006). Analysis of the modeling methodologies for predicting the sewing thread consumption. International Journal of Clothing Science and Technology, 18(1), 7-18

[9] Jaouachi. B., Khedher, F. \& Mili, F. (2012). Consumption of the sewing thread of Jean pant using Taguchi design analysis. Autex Research Journal, 12(4), 81-86

[10] Jaouachi, B., Aouine, S., Kheder, F. (2017). Consumed sewing thread behaviour based on lockstitch and chainstitch. Indian Journal of Fibre \& Textile Research, 42, 325-334.
[11] Kumar, S., Chatterjee, K., Padhye, R., Nayak, R. (2016). Designing and development of denim fabrics: Part 1 - Study the effect of fabric Parameters on the fabric characteristics for women's wear, Journal of Textile Science \& Engineering, 6(4): 265. doi: 10.4172/2165-8064.1000265.

[12] Khedher, F., Jaouachi, B. (2014). Waste factor evaluation using theoretical and experimental jean pants consumptions. The Journal of Textile Institute. http://dx.doi. org/10.1080/00405000.2014.924225

[13] BSEN 1049-2. (1993). Textiles. Woven fabrics Construction. Methods of analysis. Determination of number of threads per unit length

[14] BS EN 12127:1997; Textiles - Fabrics - Determination of mass per unit area using small samples; German version

[15] ISO 5084. (1996). Textiles - Determination of thickness of textiles and textile products. International Organisation for Standarsation.

[16] ISO 13934-1. (2013). Textiles-Tensile properties of fabrics - Part 1: Determination of maximum force and elongation at maximum force using the strip method. International Organisation for Standarsation.

[17] Sohanur Md Rahman Sobuj, (2015). Relation between yarn count and diameter \& count calculation for ply yarn. Retrieved from 2015. Web site: https://textilestudycenter. com/relation-between-yarn-count-and-diameter/

[18] Gazzah M. (2015). "Study of the effect of wire/wire friction on the behavior of Denim tissue poaching" (PhD thesis in Textile Engineering). University of Monastir. Tunisia.

[19] Kennon, W. R., Hayes S. G. (2000). The effects of feed retardation on lockstitch sewing, Journal of Textile Institute, 91, 509-522

[20] Hayes, S.G. (2001). The Effects of check-spring travel on lockstitch sewing. Research Journal of Textile and Apparel, 5(2), 54-64

[21] André Lauriol, Initiation à la technologie des matériels dans les industries de l'habillement. 1989, Edition Vauclair (Paris), pp: 151-154.

[22] Goldnfiber, (2018.) Major factors for doing sewing thread consumption. Web site: http://www.goldnfiber. com/2016/07/major-factors-for-doing-sewing-threadconsumption.html

[23] NFG 07-117. (1981). Method of assessing of fabric threads slippage and measurement of the seam resistance. French Association for Standardization AFNOR. 201-209.

[24] Stylios, G., Sotomi, J. O. (1996). Thinking sewing machines for intelligent garment manufacture. International Journal of Clothing Sciences and Technology, 8 (1/2), 44-55.

[25] Webster, J., Laing, R. M., Niven, B. E. (1998). Effects of repeated extension and recovery on selected physical properties of ISO-301 stitched seams. Part I: load at maximum extension and at break. Textile Research Journal, 68, 881-888. 